\section{Prevalence and types of eye diseases identified by routine screening of medical practitioners in Kano, Northwestern Nigeria}

\author{
Usman Abubakar Mijinyawa, ${ }^{1}$ \\ Lawan Abdu, ${ }^{2}$ Musbahu Sani Kurawa, ${ }^{2}$ \\ Zayyad Farouq ${ }^{3}$ \\ ${ }^{1}$ Department of Ophthalmology, Murtala \\ Muhammad Specialist Hospital Kano; \\ ${ }^{2}$ Department of Ophthalmology, Faculty \\ of Clinical Sciences, College of Health \\ Sciences, Bayero University Kano; \\ ${ }^{3}$ Department of Ophthalmology, Aminu \\ Kano Teaching Hospital, Kano, Nigeria
}

\begin{abstract}
Ocular screening can identify both nonblinding and potentially blinding conditions. Asymptomatic eye conditions could be detected early and be refer for further reevaluation if identified during screening. Programmed Data generated during CME in Kano were collated and analyzed. Visual acuity was done, and near vision was tested with N-chart. All the participants that needed the screening had slit lamp examination, fundoscopy, and refraction. A total number of 92 participants were examined. Age ranges from 20 to 70 years with mean age of $45 \pm 2 \mathrm{SD}$, and male to female ratio of $(\mathrm{M}: \mathrm{F}=$ $1: 0.2$ ). Emmetropia was seen in $34.8 \%$, while presbyopia was seen in $23.9 \%$ of cases. Findings were corneal opacity, cataract, and allergic conjunctivitis. Vertical cup disc ratio of $\geq 0.5$ was seen in $12.0 \%$ and $9.8 \%$ of cases in right and left eye respectively, while $1.1 \%$ of the eyes had macula hole. Refractive error for distance, presbyopia and some anterior and posterior segment findings were identified. Majority had normal vision in both eyes with visual acuity of $6 / 6$ to $6 / 18$.
\end{abstract}

\section{Introduction}

Screening is often aimed at detecting diseases some of which are asymptomatic. It could lead to early disease recognition that needed an immediate form of intervention or prompt referral for further management. Eye conditions such as cataract, refractive errors, allergy, optic disc changes that are suspicious of glaucoma were identified in other studies. ${ }^{1,2}$ In an outreach program conducted in Abuja, it was found that major causes of ocular morbidity were refractive error (40.4\%), Allergic conjunctivitis $(18 \%)$, and cataract $(3.0 \%) .{ }^{3}$ A Study in Sokoto on prevalence of blindness reported that cataract was the leading cause of unilateral blindness accounting for $53.8 \%$, non-trachomatous corneal opacity in $12.9 \%$, and uncorrected aphakia in $10.5 \% .{ }^{4}$ In Imo Nigeria, an outreach program identified that common causes of ocular morbidity were refractive error $31.6 \%$, glaucoma $23.5 \%$, presbyopia $17.0 \%$, and cataract $12.5 \% .^{5}$ There were $27.7 \%$ glaucoma suspect, and refractive error accounted for $29.6 \%$ of those with visual impairment in a study reported from Benin. ${ }^{2}$ In ECWA eye hospital Kano, most common causes of blindness were cataract $40.5 \%$, glaucoma $29.3 \%$, and corneal opacity $14.3 \%$ of cases of bilateral blindness. ${ }^{6}$ Screening done during world glaucoma week in Osun reported that $91.9 \%$ had normal disc, $7.3 \%$ had cup disc ratio $>0.6$, pale disc non cupped in $0.8 \%$, while $98.8 \%$ had normal macula. ${ }^{7}$

Medical doctors most times don't have time to go for screening as such asymptomatic eye conditions could be detected early and be refer for further reevaluation if identified in screening.

\section{Materials and Methods}

This was a cross sectional study of Medical doctors that attended the $1^{\text {st }}$ quarter Continuous Medical Education (CME) Program in Kano 2018. Ethical approval obtained from the Ethical Review Board of the State Hospitals Management Board and adhered to the tenants of Helsinki declaration. Permission was granted by the Nigerian Medical Association (NMA) Kano Branch. Programmed Data generated during the CME were collated and analyzed. All Medical doctors with registered phone contact from the database of the association were informed via text messages on the need for voluntary eye screening exercise. Screening was done in a nearby room which ensured smooth flow of participants from the waiting area to first stage assessment and refraction, then to the ophthalmologist for further examination and provision of any available intervention where needed.

The Ophthalmic nurses carried out the unaided and pinhole visual acuity using the Snellen's lettered chart and near vision using the N-Chart after informed verbal consent. The Optometrist refracted all the participants using manual retinoscope, while the Ophthalmologist carried out the slit lamp examination and fundoscopy (Welch-Allyn). Those found to have minor treatable eye conditions were treated in the venue, while those that needed reevaluation
Correspondence: Usman Abubakar Mijinyawa, Department of Ophthalmology, Murtala Muhammad Specialist Hospital Kano, Nigeria.

Tel.: +234.8035558591.

E-mail: usmanmijinyawa78@gmail.com

Key words: Ocular screening, Refractive error, Blindness.

Contributions: The authors contributed equally.

Conflict of interest: The authors declare no potential conflict of interest.

Funding: None.

Received for publication: 10 January 2019.

Revision received: 17 October 2019.

Accepted for publication: 17 October 2019.

This work is licensed under a Creative Commons Attribution NonCommercial 4.0 License (CC BY-NC 4.0).

${ }^{\circ}$ Copyright: the Author(s), 2019

Licensee PAGEPress, Italy

Pyramid Journal of Medicine 2019; 2:37

doi:10.4081/pjm.2019.37

were referred to the participating based hospitals. Data obtained included age, gender, refractive status, anterior segment findings, and vertical cup disc ratio which were all documented. Data was analyzed using a computer based statistical package for the social science (SPSS) version 16.0 (Chicago, USA). The qualitative variables are presented as bar charts, pie charts, and percentages. The non-parametric test $\chi^{2}$ was used appropriately to compare proportions. A confidence interval of $95 \%$ was used, and a P-value of $\leq 0.05$ was considered statistically significant.

\section{Results}

A total number of 173 doctors that were registered by the NMA attended the CME program, and $92(53.2 \%)$ participants were examined during the screening program. Age ranges from 20 to 70 years with mean age of $45 \pm 2 \mathrm{SD}$. There were 76 male and 16 females: (M: $\mathrm{F}=1: 0.2)$. Of 184 eyes, 1 $(1.1 \%)$ had macula hole, $3(3.3 \%)$ eyes could not be accessed due to cataract, and $88(95.7 \%)$ were normal.

\section{Discussion}

Ocular screening can identify both nonblinding and potentially blinding conditions. Despite the wide age range, most of the participants are in the third to fourth decade of life (Table 1). At these age people are more energetic. Few were in the sixth to 
seventh decade, perhaps as older doctors have retired and need not to attend the CME activity. There were more male doctors than females that attended the program in line with the general educational trend in the part of the country the study was conducted partly due to cultural reasons. Due to the relatively young age of the participants, one third were emmetropic and only one fourth had presbyopia (Table 2). Distant Refractive error occurred about equal as

Table 1. Age distribution of 92 participants.

\begin{tabular}{lc} 
Age (years) & Frequency, n (\%) \\
$20-30$ & $16(17.4)$ \\
$31-40$ & $38(41.3)$ \\
\hline $41-50$ & $16(17.4)$ \\
$51-60$ & $18(19.6)$ \\
\hline $61-70$ & $4(4.3)$ \\
Total & $92(100)$
\end{tabular}

Table 2. Refractive status.

\begin{tabular}{lc}
$\begin{array}{lc}\text { Refractive status } \\
\text { n (\%) }\end{array}$ & $\begin{array}{c}\text { Frequency, } \\
\text { Presbyopia only }\end{array}$ \\
Presbyopia with Distance refraction & $18(19.9)$ \\
\hline Distance refraction only & $20(21.7)$ \\
Emmetropia & $32(34.8)$ \\
\hline Total & $92(100)$ \\
\hline
\end{tabular}

presbyopia. In Imo refractive error accounted for $31.6 \%$ of cases, while presbyopia accounted for $17.0 \%$ of cases. ${ }^{5}$ Refractive error accounted for $29.6 \%$ of those with visual impairment in a study reported from Benin. ${ }^{2}$ The age of the participants could have accounted for the variation between the studies. More than half of the participants examined had normal anterior segments. Our study showed that allergic conjunctivitis, lens opacity, and corneal opacity were the frequent anterior segment findings (Table 3). Similarly, in an outreach program conducted in Abuja, it was found that major causes of ocular morbidity were refractive error (40.4\%), allergic conjunctivitis (18\%), and cataract $(3.0 \%) .{ }^{3}$ In Imo $^{5}$ cataract was responsible for $12.5 \%$ of cases which was nearly similar to our findings (Table 3 ). In ECWA eye hospital Kano, most common causes of blindness were Cataract $40.5 \%$, glaucoma $29.3 \%$, and corneal opacity $14.3 \%$ of cases of bilateral blindness. ${ }^{6}$ Most of the participants had vertical cup disc ratio of $\leq 0.4$ (Table 4 ), comparable to a screening study done in Osun were 91.9\% had normal disc, $7.3 \%$ had cup disc ratio $>0.6 .^{7}$ In Imo glaucoma was identified in $23.5 \%$ of cases. ${ }^{5}$ In Benin, $27.7 \%$ cases of visual impairment were found to be glaucoma suspects. ${ }^{2}$ In this study normal macular was seen in $95.7 \%$ of cases, similarly to the study in Osun ${ }^{7}$ were $98.8 \%$ of cases had

Table 3. Anterior segment findings.

\begin{tabular}{lcc} 
Anterior segment findings & $\begin{array}{c}\text { Right eye } \\
\text { Frequency, n (\%) }\end{array}$ & $\begin{array}{c}\text { Left eye } \\
\text { Frequency, n (\%) }\end{array}$ \\
Normal & $52(56.5)$ & $50(54.3)$ \\
Corneal opacity & $1(1.1)$ & $1(1.1)$ \\
\hline Cataract & $10(10.9)$ & $10(10.9)$ \\
Allergic conjunctivitis & $29(31.5)$ & $29(31.5)$ \\
\hline Other findings & $0(0)$ & $2(2.2)$ \\
Total & $92(100)$ & $92(100)$ \\
\hline
\end{tabular}

Table 4. Vertical Cup Disc in 184 eyes of 92 participants.

\begin{tabular}{lcc} 
Cupp disc ratio & $\begin{array}{c}\text { Right eye } \\
\text { Frequency, n (\%) }\end{array}$ & $\begin{array}{c}\text { Left eye } \\
\text { Frequency, n (\%) }\end{array}$ \\
$\leq 0.4$ & $79(85.9)$ & $82(89.1)$ \\
$\geq 0.5$ & $11(12.0)$ & $9(9.8)$ \\
\hline No red reflex & $2(2.2)$ & $1(1.1)$ \\
Total & $92(100)$ & $92(100)$ \\
\hline
\end{tabular}

Table 5. Vision status of 92 participants.

\begin{tabular}{lcc} 
Cupp disc ratio & $\begin{array}{c}\text { Right eye } \\
\text { Frequency, n (\%) }\end{array}$ & $\begin{array}{c}\text { Left eye } \\
\text { Frequency, n (\%) }\end{array}$ \\
Normal vision & $90(97.8)$ & $89(96.7)$ \\
Moderate visual impairment & $0(0)$ & $1(1.1)$ \\
\hline Blindness & $2(2.2)$ & $2(2.2)$ \\
Total & $92(100)$ & $92(100)$ \\
\hline
\end{tabular}

normal macula. In our screening only one case of macular hole was identified, and in $3.3 \%$ of cases the macular could not be accessed due to cataract. Uniocular blindness was only seen in $2.2 \%$ of right eye, while $97.8 \%$ had normal vision in the right eye. In the left eye $96.7 \%$ as well had normal vision, while $2.2 \%$ had uniocular blindness. Moderate visual impairment was seen in $1.1 \%$ of cases (Table 5 ).

\section{Conclusions}

From the study, eye conditions such as refractive error for distance, presbyopia and some anterior segment findings (corneal opacity, cataract and allergic conjunctivitis) were identified. Some of the participants had a vertical cup disc ratio of $\geq 0.5$. while uniocular blindness was seen in $2.2 \%$ of cases, and about $90 \%$ of the participants had normal vision in both eyes. Of the 184 eyes examined, only $1.1 \%$ had macula hole.

\section{References}

1. Ogwurike S, Pam V. Pattern of eye diseases in Kaduna State, a rural community outreach experience. Nig J Ophthal 2004;12:1-5.

2. Osaguona VB, Ukponmwan CU, Kayoma DH, Okojie OH. Ocular health status of patients seen at the screening Centre of the University of Benin Teaching Hospital Benin city, Nigeria A preliminary report. J Biomed Sci 2012;11:44-50.

3. Babalola OE, Babalola IB, Esuga M, et al. Finding in an eye care outreach programme in Abuja. Nig J Ophthal 2003; $11: 12-5$.

4. Muhammad M, Mansur RM, Dantani $\mathrm{AM}$, et al. Prevalence and causes of blindness and visual impairment in Sokoto state, Nigeria, Baseline data for Vision 2020: The right to sight eye care programme. Mid Est Afr J Ophthalmol 2011;18:123-8.

5. Achigbu EO, Dike KC, Uwakwem AC, et al. Ocular morbidity in rural communities in Imo state, south east Nigeria. Open J Ophthalmol 2016;6:184-90.

6. Olatunji FO, Kirupananthan $\mathrm{S}$, Ayanniyi AA, Abuh S. Causes of adult blindness at ECWA eye hospital Kano, Nig J Ophthalmol 2008;16:51-4.

7. Isawumi MA, Hassan MB, Asekunolarinmoye EO, et al. Prevalence and causes of ocular morbidity seen among rural adult population of Osun state, south west Nigeria. Ann Trop Med Pub Health 2013;6:465-71. 